\title{
The Role of Using Case Studies Method in Improving Students' Critical Thinking Skills in Higher Education
}

\author{
Omar Rabeea Mahdi ${ }^{1}$, Islam A. Nassar ${ }^{1} \&$ Hashem Ali Issa Almuslamani $^{1}$ \\ ${ }^{1}$ College of Administrative Sciences, Applied Science University, Kingdom of Bahrain \\ Correspondence: Omar Rabeea Mahdi, College of Administrative Sciences, Applied Science University, 23East \\ Al-Ekir, Kingdom of Bahrain. E-mail: omar.almafrachi@asu.edu.bh.
}

Received: October 29, 2019

Accepted: March 5, 2020

Online Published: March 9, 2020

doi:10.5430/ijhe.v9n2p297

URL: https://doi.org/10.5430/ijhe.v9n2p297

\begin{abstract}
Investigating the use of case studies as a teaching strategy to enhance the critical thinking skills of the students is the basic objective of this study. By discovering content and procedural issues, best practices are investigated and ways are discovered to foster critical thinking, as a result of which the students tend to develop the ability to think critically. This research employed mixed research methods and used the SPSS program for data analysis. The participants in this research are 42 students from the business management program of leadership and group dynamics course in applied sciences university (ASU) in the kingdom of Bahrain. Based on the research findings, the critical thinking skills of the students have been a consequence of the case study method. The findings of this research may have significant value for other higher education institutions in the wider Gulf region. If the case studies method is used in teaching, it will greatly contribute to the leadership and group dynamics educators in nurturing active learning. Additionally, it is likely to inculcate critical thinking skills, which are highly significant to develop leadership capabilities.
\end{abstract}

Keywords: case-based learning, group case study discussion, critical thinking

\section{Introduction}

In recent times, one of the topics among a number of academic articles is the development of critical thinking (Schmaltz, Jansen, \& Wenckowski, 2017; Walker, 2003). According to different studies, different skills are possessed by the students to grasp critical thinking questions (Tilus, 2012). Apparently, the academics delivering postgraduate level study program are of the view that a key and fundamental goal of education among students is the development of critical thinking ability (Biggs \& Tang, 2011). According to the findings of economists, the analytical individuals who can think from an abstract position are significantly valued by the labor market. Nowadays, particularly business management students prior to their graduation should demonstrate mastery of critical thinking abilities (Taleb \& Chadwick, 2016). Critical thinking is a capability which is being required by students in their personal and professional life. Therefore, universities must do their most to include it in their classes, programs, and syllabus (Bezanilla, Fernández-Nogueira, Poblete, \& Galindo-Domínguez, 2019).

In their midterm and final exams, finding the solution to the critical thinking questions becomes a difficult task for the students at ASU especially at level 4. Moreover, it usually takes too long to answer the questions during the examination. The thought and active learning in the classroom can be promoted through various instructional methods, which may include: problem-solving, case study, discussion methods, debates, written exercises, and questioning techniques (Tilus, 2012). The active participation and critical thinking can be facilitated with these learning strategies, although they are not suitable for every class and every subject matter. One of the teaching strategies is the case study, which is emphasized by the academic experts to nurture critical thinking skills of the students (Walker, 2003), and the benefits can be realized by practical application of theory (Biggs and Tang, 2011, p. 186).

The case study teaching method is a highly adaptable style of teaching that involves problem-based learning and promotes the development of analytical skills (Herreid, Schiller, Herreid, \& Wright, 2011). By presenting content in the format of a narrative accompanied by questions and activities that promote group discussion and solving of complex problems, case studies facilitate the development of the higher levels of Bloom's taxonomy of cognitive learning; moving beyond recall of knowledge to analysis, evaluation, and application (Bonney, 2015). Similarly, case 
studies facilitate interdisciplinary learning and can be used to highlight connections between specific academic topics and real-world societal issues and applications (Bonney, 2013; Herreid et al., 2011). This has been reported to increase student motivation to participate in class activities, which promotes learning and increases performance on assessments (Fynn \& Klein, 2001; Murray-Nseula, 2011; Yadav et al., 2007). For these reasons, case-based teaching has been widely used in business education for many years (Bridgman, Cummings, \& McLaughlin, 2016; Carlson \& Schodt, 1995; Hammond, 2002; Knechel, 1992; Pilz \& Zenner, 2018). Despite what is known about the effectiveness of case studies in science education, questions remain about the functionality of the case study teaching method at promoting specific learning objectives that are important to many undergraduate business management courses.

To offer the solutions to the current research problems related with critical thinking skills to course of leadership and group dynamics to students at ASU and to tackle the mentioned issues, the research scholars had identified and formulated the research question in this manner: how successfully the critical thinking skills of the students can be improved by the case studies method in course of leadership and group dynamics students in ASU? Hence, determining the output of using cause study methods in improving students' critical thinking skills is the main objective of the research. The students in the course of leadership and group dynamics will be the beneficiaries of the research program. A number of highly critical thinking lessons are included in this course, those are vital to analyze the information on a well-organized scale.

\section{Litterateur Review}

\subsection{Critical Thinking Skills}

There is no standard, universally accepted, all-inclusive framework or set of criteria by which to describe or evaluate critical thinking (Myrick, 2002). The authors have suggested wide-ranging critical thinking definitions and viewpoints (Kaddouro, 2011). According to Profetto-McGrath (2003), cognitive skills and attitudes have been described in the definition of critical thinking. In this context, Nieto and Saiz (2011) define critical thinking as a set of cognitive skills and dispositions of the highest order, different from those of lower order or more simple skills. Further, it is active learning strategies promote critical thinking by triggering cognitive processes (Youngblood \& Beitz, 2001). Critical thinking is purposeful thinking in which individuals systematically and habitually impose criteria and intellectual standards upon their thought (Paul, 1993; Popil, 2011). Critical thinkers possess the following characteristics: they are "outcome-driven, open to new ideas, flexible, willing to change, innovative, creative, analytical, communicators, assertive, persistent, caring, energetic, risk-takers, knowledgeable, resourceful, observant, intuitive, and 'out of the box' thinkers (Ignatavicius, 2001). According to Giancarlo and Facione (2001), critical thinking is a self-directed and well-organized cognitive process that leads to high-quality findings and decisions, which can be realized through the evaluation, investigation, measurement, and reformulation of thinking. For this study, the operational definition of critical thinking can be traced from Facione (2006), which comprises the ability to analyze, synthesize, infer, and evaluate the situations.

The critical thinking can be observed in several ways, however, it is first and foremost viewed as a process instead of an objective or an endpoint (Petress, 2004). Critical thinking is not limited to knowledge areas, disciplines, or experiences and occurs within and across all these domains (Paul \& Elder, 2013). The reflection both on knowledge and experience tends to develop critical thinking. As shown by Zelaieta Anta and Camino Ortiz de Barrón (2018), critical thinking is a reflective activity that leads to action and that in order to develop it students must think about what they think. Universities should encourage students on how to think and not what to think. To think critically is a process, and its acquisition takes time. Within this process, university teachers must be aware of the need for a transformation to adjust their teaching methodologies to the learning of their students, as their way of thinking may generate fixed routines in their teaching practices. That is, the teacher must also reflect on their practices and introduce different and varied methodologies (Bezanilla et al., 2019). According to Facione (2006), critical thinking skills can be taught and learned. When the active teaching strategies and lecture-based teaching are used together, for instance, group discussion and analytical questioning, it results in knowledge acquisition and students can achieve great benefits (Kaddouro, 2011). The case study is one of the methods that use to teach and learn critical thinking skills (Popil, 2011).

\subsection{Case Study Method}

As per the findings of Leenders, Mauffette-Leenders and Erskine (2001), an account of a real situation, usually containing a challenge, a decision, an opportunity, or a problem encountered by a person or persons in an organization is usually described as the case study. It is also known as a case, case study strategy, case method or case study method (Popil, 2011). In the 1870s, the Harvard school faculty had introduced this term and it has been used for many years in business and law schools at Harvard University (Kaddouro, 2011). A case study is a research 
methodology that has commonly used in social sciences (Devare, 2015; Shareia, 2015). Case studies have been largely used in the social sciences and have been found to be especially valuable in practice-oriented fields (such as education, management, public administration, and social work). But despite this long history and widespread use, case study research has received little attention among the various methodologies in social science research (Biba, 2013; Ebneyamini \& Sadeghi Moghadam, 2018; Tight, 2010). Cases do not give simple or explicit answers; rather, they provoke students' critical thinking, illustrate how to think professionally and urge students to use theoretical concepts to highlight a practical problem. The case study method has unique features such as; it is based on real-life scenarios, provides supporting data and documents to be analyzed, and an open-ended question or problem is presented for a possible solution. Case studies often are long and detailed, describing fairly well-defined problems. Learners can apply their background knowledge as well as new learning to solve the problem (DeYoung \& DeYoung, 2003). Case studies can be presented to individuals or groups; most commonly, however, they are worked on in groups that can brainstorm solutions to problems/questions presented. Cases have different types, which usually range from straightforward situations to difficult scenarios. Some of the scenarios may contain real-life data and role play (Popil, 2011). They engage the learners and enable them to apply theory to practice, practice decision making skills to specific problems, use different perspectives, participate in data analysis, and synthesize course content (Grupe \& Jay, 2000; Kaddouro, 2011).

Gaining an insight, learning new things, improving the listening and cooperative learning skills, fostering partnerships among learners and teachers, uplifting the attention toward ideas and assumptions, carefully thinking ideas and evaluating them besides stimulating brainstorming and thinking are the different courses of action which can be understood while working on cases and scenarios (Grupe \& Jay, 2000). For instance, student-teacher interaction is improved by discussing the cases. In this way, students are likely to develop critical thinking and they take part in discovering possible solutions. The different perspectives can be taken to explore different ideas.

To facilitate students' learning besides teaching them to decide about their perspective field, an instructional method within the context of student-centered learning is none other than the Case-Based Learning (CBL). The benefits can be realized with the use of case studies (Kaddouro, 2011). Learning through the means of Case-Based Learning helps students to build on prior knowledge, integrate knowledge, and consider an application to future situations (Vora \& Shah, 2015). Accountability and teamwork are promoted by the cases, and hence the adult learners become inspired to critically think and meticulously learn about reasonable answers rather than inactively receiving the facts (Bastable, 2003).

\subsection{Case Study Method and Critical Thinking Skills}

According to DeYoung and DeYoung (2003), cases do not provide simple or exact solutions, rather they give simple or explicit answers; rather, they instill the need in students to think critically and professionally by implementing theoretical concepts to present a practical issue. Cases create the need to know, enhancing the listening and cooperative learning skills of the students, building partnerships among learners and teachers, encouraging attention to and self-consciousness toward assumptions and conceptions, help students learn to monitor their own thinking, and promote thinking and brainstorming (Grupe \& Jay, 2000). White et al. (2009) stated that case studies have wide value in classrooms. In addition, in their study, they also showed a major increase in the number of students who critically analyzed and evaluated in thinking demonstrated that there is a statistically significant increase in the number of students capable of critical analysis and evaluation in thinking. Kaddouro (2011) examined the critical thinking capabilities of nursing students from two different curricular approaches, Case-Based Learning (CBL) and traditional didactic teaching (Lecture-Based Teaching). He concluded that participants who learned by Case-Based Learning (CBL) performed better in the total critical thinking score and all critical thinking subscales than the traditional program participants. A positive outcome of this study was the finding that the Case-Based Learning (CBL) methodology appeared to be more effective in developing critical thinking skills for nursing students than the traditional lecture-based teaching methodology. Popil (2011) was also argued that using case studies in teaching assists educators in promoting and developing active learning critical thinking skills. Pilz and Zenner (2018) investigate the extent to which using case study method can help to promote networked thinking in business education. Networked thinking takes account of interactions and repercussions, making it crucial to decision-making within the complex system of rules that shapes current business reality. Case studies promote problem-solving skills, higher-order thinking skills or critical thinking skills, which form the basis for networked thinking. Students from business management courses are presumably educated to become decision-makers in a complex world. Networked thinking skills form an essential basis to handle complex situations and hence to make profound and informed decisions. The findings demonstrated that the use of case studies did promote students' networked thinking. Post-testing identified significantly more propositions than pre-testing. Therefore, they concluded that students on 
business and management courses who have worked on a case study correctly identified more interactions in post-testing than in pre-testing. In their study, Allen and Toth-Cohen (2019) provided further support for the use of case studies to promote critical thinking. They found that case studies by using the form of increasingly independent engagement may assist reduce anxiety and improve confidence and critical thinking. Also, in the same study, they indicated that students found the case studies assist to develop and apply critical thinking to their fieldwork experiences. Therefore, in the light of above literature review, it is hypothesized that case study method effectively promotes critical thinking skills:

$H_{1}$ : The case study method has a significant role in enhancing students' critical thinking skills in Higher Education.

\section{Method of Research}

This research includes both quantitative and qualitative methods to collect data regarding the critical thinking skills of students. As stated by Gibbert, Ruigrok and Wicki (2008), mixed methods aids in reducing the researcher's bias and increasing the construct validity. It allows the researcher to investigate the phenomenon from different angles, and thus minimize researcher bias. Quantitative method aids in determining the number of learners using critical thinking skills and examines the pre-learning and post-learning ability as well. Besides that, the qualitative method helps provide more information for lecturers to enhance critical thinking skills in their students. For example, the tacit nature of teaching in the classroom relies on teachers' judgments that are open to the multiple interpretations of symbolic interactionism rather than rigorously measured causality. Therefore, a researcher interested in asking why and how questions may instead look to qualitative approaches to answer their research question. These focus on meanings, perspectives, and understandings of social and cultural phenomena (Scoles, Huxham, \& McArthur, 2014). On the other hand, the qualitative method is useful in highlighting the areas of students' learning and skills that quantitative measures cannot by using multiple-choice formats (Behar-Horenstein \& Niu, 2011). According to Creswell (2007), mixed methods research is a research design with philosophical assumptions as well as methods of inquiry. As a methodology, it involves philosophical assumptions that guide the direction of the collection and analysis of data and the mixture of qualitative and quantitative approaches in many phases in the research process. As a method, it focuses on collecting, analyzing, and mixing both quantitative and qualitative data in a single study or series of studies. Its central premise is that the use of quantitative and qualitative approaches in combination provides a better understanding of research problems than either approach alone. Yin (2003) stated that the case study inquiry is only successful when be built on the collection and analysis of data from multiple sources. He emphasizes that case studies may be based on any combination of quantitative and qualitative evidence. Hence, case studies provide a larger amount of data that covers various aspects Behar-Horenstein and Niu (2011). A triangulation of data collection techniques was used by including both qualitative and quantitative information that would provide authentic case findings. Therefore, this case study used both methods to collect information from classroom tests, supervised self-administered questionnaire, and one-to-one interviews. The data collection tools are discussed in next section.

\subsection{Test}

The test has been carried out in three phases, pre cycles, cycle 1, and cycle 2. In pre cycles, students were required to introduce pre-test case studies individually to evaluate the students' critical thinking level. In cycle 1, classes with post-test group case studies were introduced. In cycle 2, classes with post-test case studies have been implemented individually.

\subsection{Questionnaire}

In this research, the supervised self-administered questionnaire has been used directly to collect data from the students. The questionnaire has been adapted with the California Critical Thinking Skills Test (CCTST) and developed to measure the critical thinking abilities of the students. The questionnaire was also used and valid by Soukup (1999) and Kaddouro (2011). The questionnaire categorized into six constructs: analysis, interpretation, evaluation, inference, inductive reasoning, and deductive reasoning. There was a total of 24 items, 4 items for each construct used to measure the critical thinking skills (see appendix 2). The present research utilized a five Likert scale of the survey questionnaire. An example of the five-point Likert scale is 1= "Strongly Disagree", $2=$ "Disagree", $3=$ "Neither Agree or Disagree", 4= "Agree", and 5= "Strongly Agree". The questionnaire proposed has been administered and distributed to students during the two cycles to see how they think critically.

\subsection{Interview}

Semi-structured interviews with two questions were carried out after finish cycles of the experiment with 6-randomly selected students at the end of the study (see appendix C). The main goal of the interviews is to see students' 
perceptions of the used case study method.

\section{Research Procedures}

The study was based on three consecutive phases: Pre-Cycle, Cycle 1 and Cycle 2. The objective of the cycles is to measure the effectiveness of using cause study methods in improving students' critical thinking skills; to enable students to practice problem-solving in analyzing case studies in their learning; and, to increase students' ability to use critical thinking skills in their learning.

\subsection{Pre-Cycle: An analysis of the Existing Condition}

At the pre cycles, for the research requirements, students were required to introduce pre-test individual case study to measure and evaluate their critical thinking level.

\subsection{Cycle 1}

In cycle 1, the research progress required approximately two weeks, it started on 19 November 2017 and finished on 3 December. The beginning of the first week has been assigned to collect data regarding using group case study discussion in the post-test which was introduced to students to improve students' critical thinking skills. Further, the ending of the first week has been used to collect data by using a questionnaire to investigate students' critical thinking skills with group case study discussion in the post-test. During the last week, the researcher analyzed and evaluated the collected data.

\subsection{Cycle 2}

In cycle 2, the research progress required approximately two weeks, it started on 4 December and finished on 25 December. The beginning of the first week has been used to collect data regarding using an individual case study in the post-test was introduced to students to improve students' critical thinking skills in teaching course of leadership and group dynamics. At the end of the first week, the data has been collected the questionnaire to investigate students' critical thinking skills with the individual case study in the post-test. At the end of the first week, the data has been collected by using an interview to get feedback about employing case study to improve students' critical thinking skills. During the last week, the researcher has been analyzed and evaluated the data to propose some suggestions to improve student's critical thinking. The data were analyzed using the SPSS software package, version 21.0. Descriptive statistics were used to analyze the data of the students. For the critical thinking scores, the minimum, maximum, mean, standard deviation, and t-test were computed.

\section{Participants}

The participants in this research are total students who were enrolled in the course of leadership and group dynamics in the program of business management in ASU during the first semester of the academic year 2017-2018. The census method was used due to the few numbers of students. Census surveys are the types of surveys involving the process of collecting information about each member of a given population (Meyer, 2002; Zhang et al., 2007). The sample of the research consisted of 40 students, 22 females (55\%) and 18 male (45\%). The average age of students in the course of leadership and group dynamics was 25 years with a range in age from 20 to 30. See Figure 1.

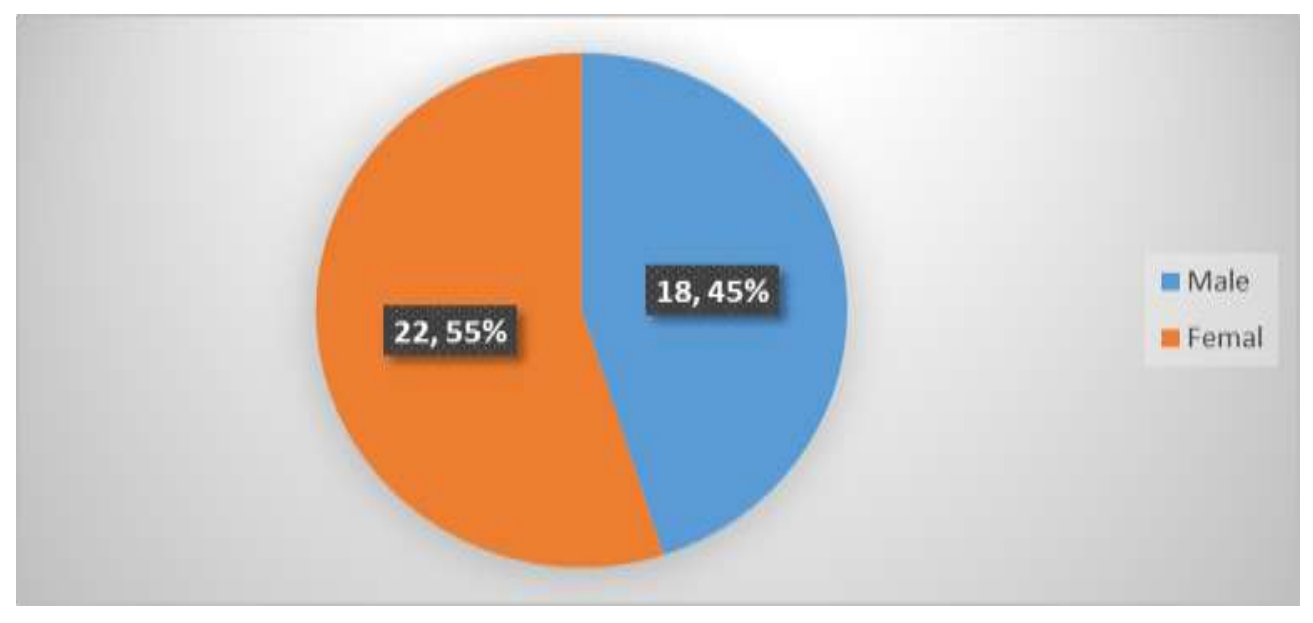

Figure 1. The Participants in Research 


\section{Results}

Analysis of the data concerning the general influences of formative feedback revealed a number of significant findings. During the research, 40 students $(100 \%)$ completed the individual pre-test in the pre-cycle. The pre-test scores for the students' critical thinking ranged from a minimum of 1 to a maximum of 5 . The grade point had a mean score of 2.425 . The percentage of students who have 1, 2, 3, 4, and 5 marks were $17 \%, 42 \%, 20 \%, 18 \%$, and $3 \%$, respectively (Figure 2).

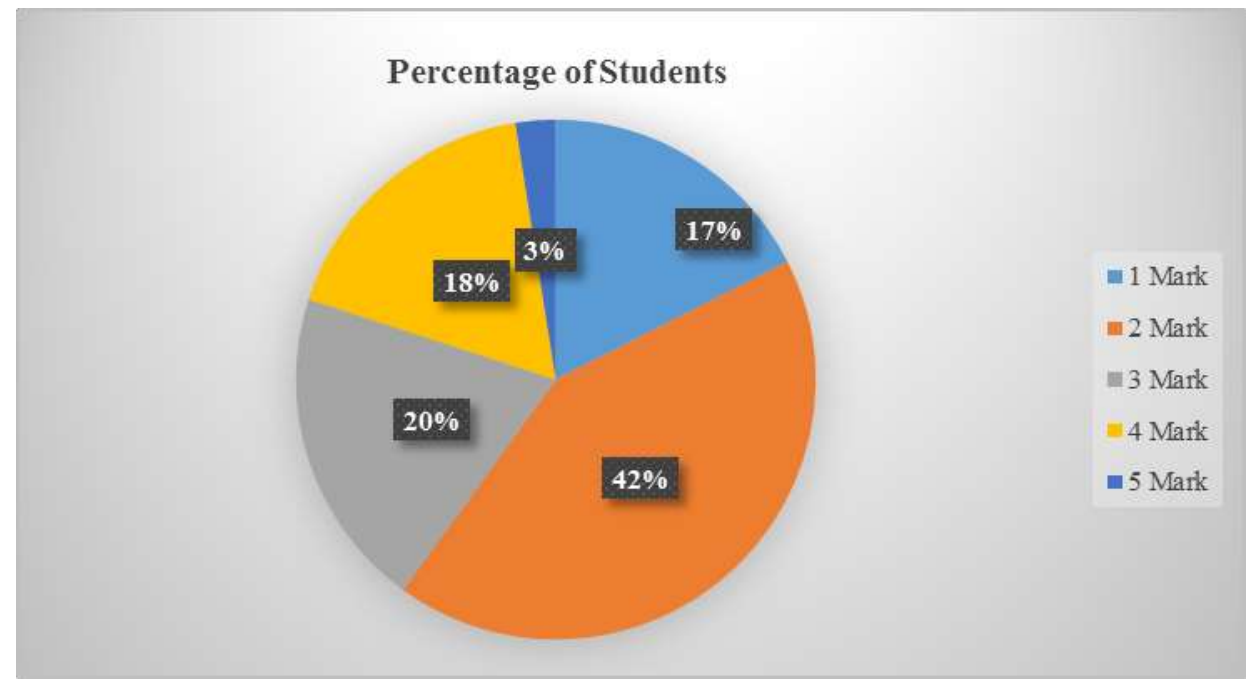

Figure 2. Pre-Test Pre Cycle

The post-test results of group case study discussion for each student are presented in Figure 3. The post-test scores of the group case study ranged from a minimum of 4 to a maximum of 6 . The post-test scores had a mean score of 5 for group case study. According to Figurer 3, the result showed that $10 \%$ of the students scored 4 marks, $55 \%$ scored 5 marks, and 35\% scored post-test marks.

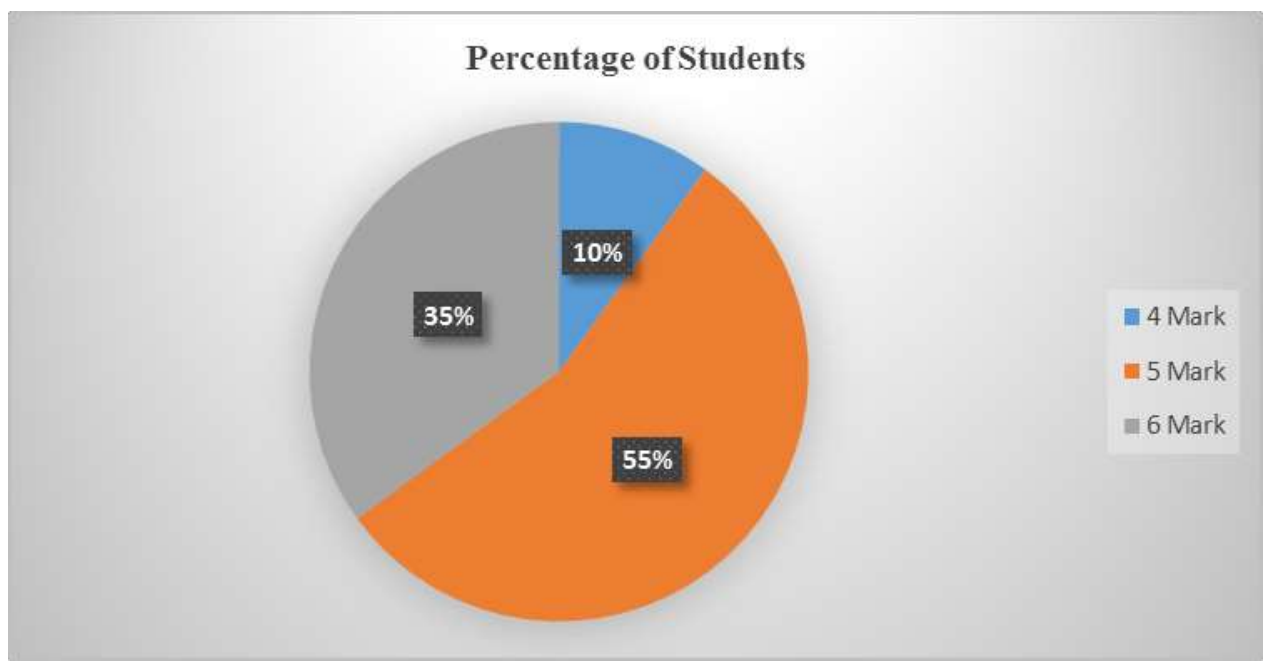

Figure 3. Post-Test Cycle 1

To assess the change in thinking skills, the mean score of individual case study in the pre-test to the mean score of group case study in the post-test. The mean score of individual case study in the pre-test had a mean of 2.43 and the mean score of group case study in the post-test had a mean 5.25. The comparison was made by subtracting the pre-test mean score from the post-test mean score for case study score. The resulting change scores were analyzed with the t-test of differences. The mean score was not identical for both tests and there was a significant difference. In other words, the results found that students' grade level with group case study post-test was better from the results of individual case study pre-test. In conclusion, students' critical thinking skills with group case study were improved and motivated. In addition, using group cause study methods was effective in improving students' critical thinking skills in the course of leadership and group dynamics. The students' scores showed a change in total 
thinking skills of 2.82 between pre-test and post-test scores on the case study score. Their t-test of differences for total thinking skills was 2.45. This t-value is significant at the $p=.02<.05$. In another word, the above results indicate that the students significantly have gained critical thinking skills. Table 1 demonstrates the comparison between pre-test and post-test in terms of the mean score, mean change, t-test, and level of significance.

Table 1. Comparison of Pre-test and Post-test

\begin{tabular}{ccccccc}
\hline Comparison & $\mathbf{N}$ & $\begin{array}{c}\text { Mean } \\
\text { Pre-test }\end{array}$ & $\begin{array}{c}\text { Mean } \\
\text { Post-test }\end{array}$ & $\begin{array}{c}\text { Mean } \\
\text { Change }\end{array}$ & t-test & $p$-value \\
\hline Case Study Score & 40 & 2.43 & 5.25 & 2.82 & 2.45 & 0.02
\end{tabular}

The total mean of critical thinking skills for the post-test with group case study was 4.35 . The total mean ranged from 4. 35 as a minimum value to 4.90 as a maximum value. The Analysis had a mean value of 4.37 , with a score ranging from 3.95 as a minimum to 4.78 as a maximum. The Interpretation had a mean score of 4.75 , with a score ranging from 4.56 to 4.94 . The Evaluation had a mean score of 4.87, with a score ranging from 4.85 to 4.89 . The Inference had a mean score of 4.37, with a score ranging from 3.98 to 4.76 . The Inductive Reasoning had a mean score of 4.88 with a score ranging from 4.90 to 4.85 . The Deductive Reasoning had a mean score of 4.77 , with scores ranging from 4.84 to 4.70 (Table 2).

Table 2. Descriptive Statistics of Critical Thinking Skills Questionnaire-Cycle 1

\begin{tabular}{clcccc}
\hline Variables & No. & Minimum & Maximum & Mean & Std. Deviation \\
\hline Analysis & 40 & 3.95 & 4.78 & 4.37 & 1.09 \\
Interpretation & 40 & 4.56 & 4.94 & 4.75 & 1.11 \\
Evaluation & 40 & 4.85 & 4.89 & 4.87 & 1.43 \\
Inference & 40 & 3.98 & 4.76 & 4.37 & 0.88 \\
Inductive Reasoning & 40 & 4.90 & 4.85 & 4.88 & 0.93 \\
Deductive Reasoning & 40 & 4.84 & 4.70 & 4.77 & 1.32 \\
Total & 40 & 4.35 & 4.90 & 4.80 & 0.75 \\
\hline
\end{tabular}

The post-test results of individual case study for each student are presented in figure 4.The post-test scores of individual case study ranged from a minimum of 3 to a maximum of 6 . The post-test scores had a mean score of 5.125 for individual case study. The percentage of students who have 3, 4, 5 and 6 marks were $2 \%, 20 \%, 40 \%$, and $38 \%$, respectively (Figure 4).

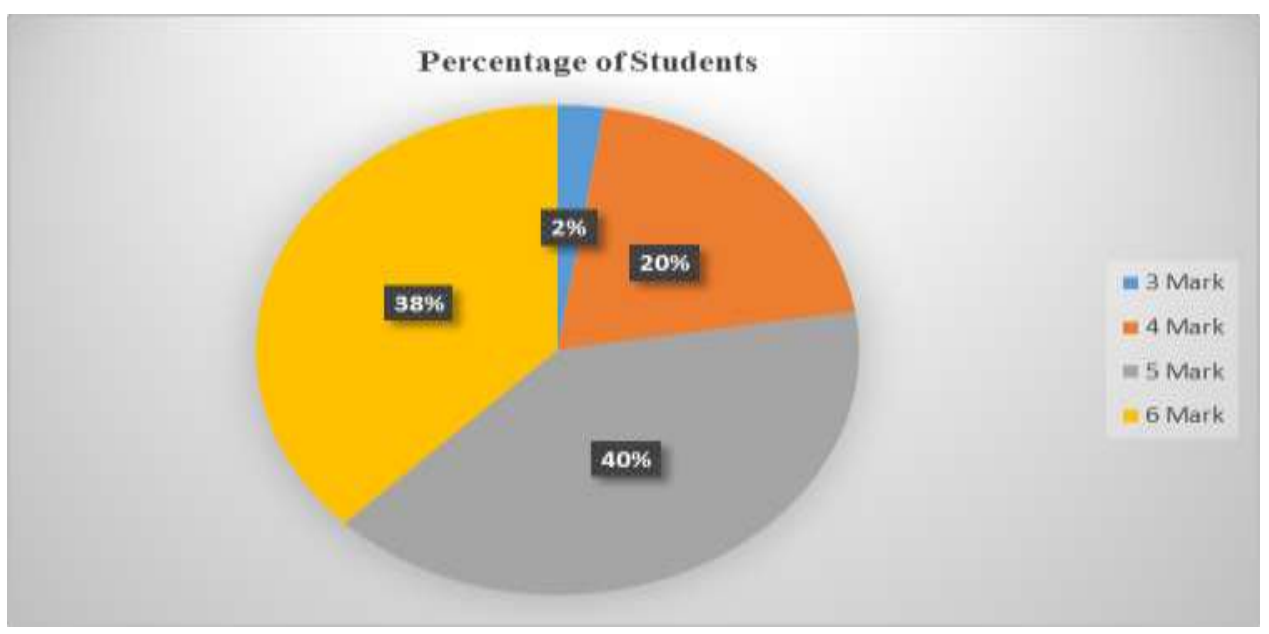

Figure 4. Post-Test Cycle 2

To assess the change in critical thinking skills, the mean score of group case study in post-test cycle 1 was compared to the mean score of individual case study in post-test cycle 2 . The mean score of group case study in post-test cycle 1 had a mean of 5.25 and the mean score of individual case study in post-test cycle 2 had a mean 5.125. The 
comparison was made by subtracting the post-test mean score in cycle 2 from the post-test mean score for case study score in cycle 2 . The resulting change scores were analyzed with the t-test of differences. The mean score was not identical for both tests and there was a significant difference. In other words, the results found that students' grade level with an individual case study post-test in cycle 2 were almost identical with the results of individual case study post-test in cycle 1 . In conclusion, using a group case study method in cycle 1 was effective in improving and developing students' critical thinking skills in introduce individual case study post-test to course of leadership and group dynamics. In addition, the case study method enables students to practice problem-solving analysis, interpretation, evaluation, inference, inductive reasoning, and deductive reasoning case studies in their learning. The students' scores showed a change in total thinking skills of -0.125 between case study's scores for both post-tests in cycle 1 cycle 2 . Their t-test of differences for total thinking skills was 0.215 . This t-value is significant at the $p=.03$ $<.05$. In another word, there is a statistically significant gain in students' critical thinking level during the course of leadership and group dynamics as measured by the total score. Table 3 demonstrates a comparison between both post-tests in cycles 1 and 2 in terms of the mean score, mean change, t-test, and level of significance.

Table 3. Comparison of Post-test Cycle 1 and Post-test Cycle 2

\begin{tabular}{|c|c|c|c|c|c|c|}
\hline & & Cycle 1 & Cycle 2 & & & \\
\hline Comparison & $\mathrm{N}$ & $\begin{array}{c}\text { Mean } \\
\text { Post-test }\end{array}$ & $\begin{array}{c}\text { Mean } \\
\text { Post-test }\end{array}$ & Mean Change & t-test & $p$-value \\
\hline Case Study Score & 40 & 5.25 & 5.125 & -0.125 & 0.215 & 0.03 \\
\hline
\end{tabular}

Figure 5 illustrates comparison results between mean values of pre-test in pre-cycle, post-test in cycle 1, and post-test in cycle 2 . The results show that the mean value for the pre-test in pre-cycle is 2.45 , and the mean value for the post-test in cycle 1 is 5.25, while the mean value for the post-test in cycle 2 is 5.125 . From Figure 5 also, it can be seen that students' mean scores for post-test in cycle 1 and cycle 2 have the highest mean scores when compared to pre-cycle. The results indicate that critical thinking skills have been developed in cycles 1 and 2. Therefore, the results illustrate that the cause study method significantly improving students' critical thinking skills. Thus, hypothesis 1 is supported.

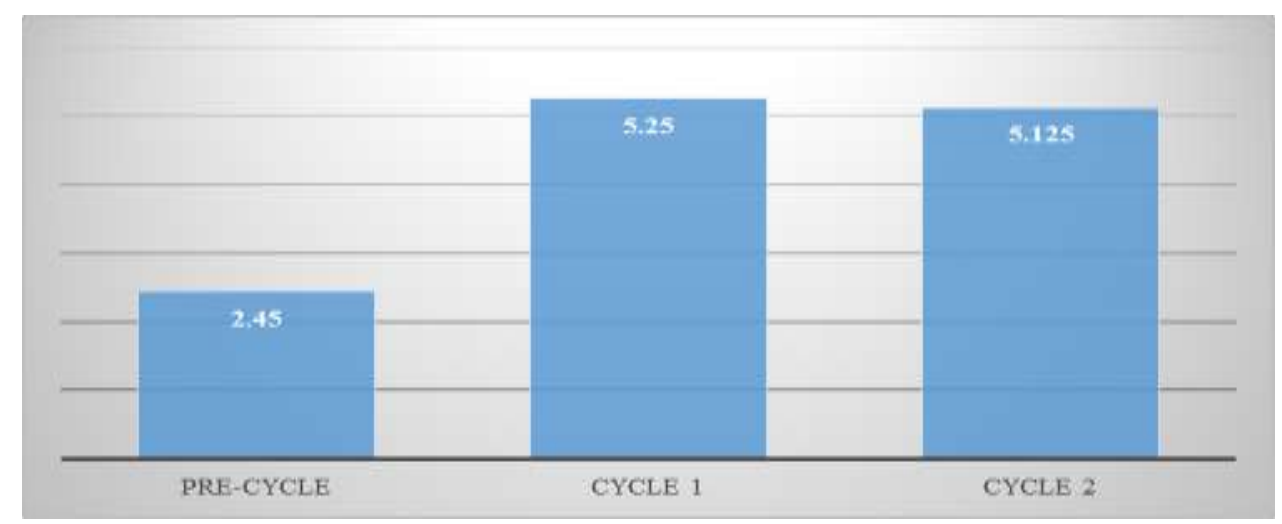

Figure 5. Comparison between Mean Values of Pre-test Pre-Cycle, Post-test Cycle 1, and Post-test Cycle 2

The total mean value of critical thinking skills for the post-test with individual case study was 4.74 . The total mean value ranged from 4. 67 as a minimum value to 4.81 as a maximum value. The Analysis had a mean value of 4.37, with a score ranging from 3.25 as a minimum to 4.37 as a maximum. The Interpretation had a mean value of 4.55 , with a score ranging from 4.21 to 4.89 . The Evaluation had a mean value of 4.00, with a score ranging from 3.63 to 4.37. The Inference had a mean value of 4.05 , with a score ranging from 4.11 to 4.89 . The Inductive Reasoning had a mean value of 4.01 with a score ranging from 3.83 to 4.18. The Deductive Reasoning had a mean score of 4.55, with scores ranging from 4.78 to 4.35 (Table 4 ). 
Table 4. Descriptive Statistics of Critical Thinking Skills Questionnaire-Cycle 2

\begin{tabular}{cccccc}
\hline Variables & No. & Minimum & Maximum & Mean & Std. Deviation \\
\hline Analysis & 40 & 3.25 & 4.37 & 3.81 & 0.76 \\
Interpretation & 40 & 4.21 & 4.89 & 4.55 & 0.82 \\
Evaluation & 40 & 3.63 & 4.37 & 4.00 & 0.32 \\
Inference & 40 & 4.11 & 4.89 & 4.05 & 0.21 \\
Inductive Reasoning & 40 & 3.83 & 4.18 & 4.01 & 0.77 \\
Deductive Reasoning & 40 & 4.78 & 4.35 & 4.55 & 0.65 \\
Total & 40 & 4.67 & 4.81 & 4.74 & 0.12
\end{tabular}

Figure 6 illustrates comparison results between both questionnaires in cycles 1 and 2 in terms of the mean and stander deviation. The results show that the mean value for cycle 1 is 4.8 while the mean value for cycle 2 is 4.74 . The standard deviation value for cycle 1 is .75 while the standard deviation value for cycle 2 is .12. From figure 6 also, it can be seen that cycle 1 has close mean value to mean value cycle 2 . The results indicate that critical thinking skills have been improved in cycle 1 and 2. Therefore, that illustrates that the role case study method was found to be significantly related to improve students' critical thinking skills. Thus, hypothesis 1 is supported.

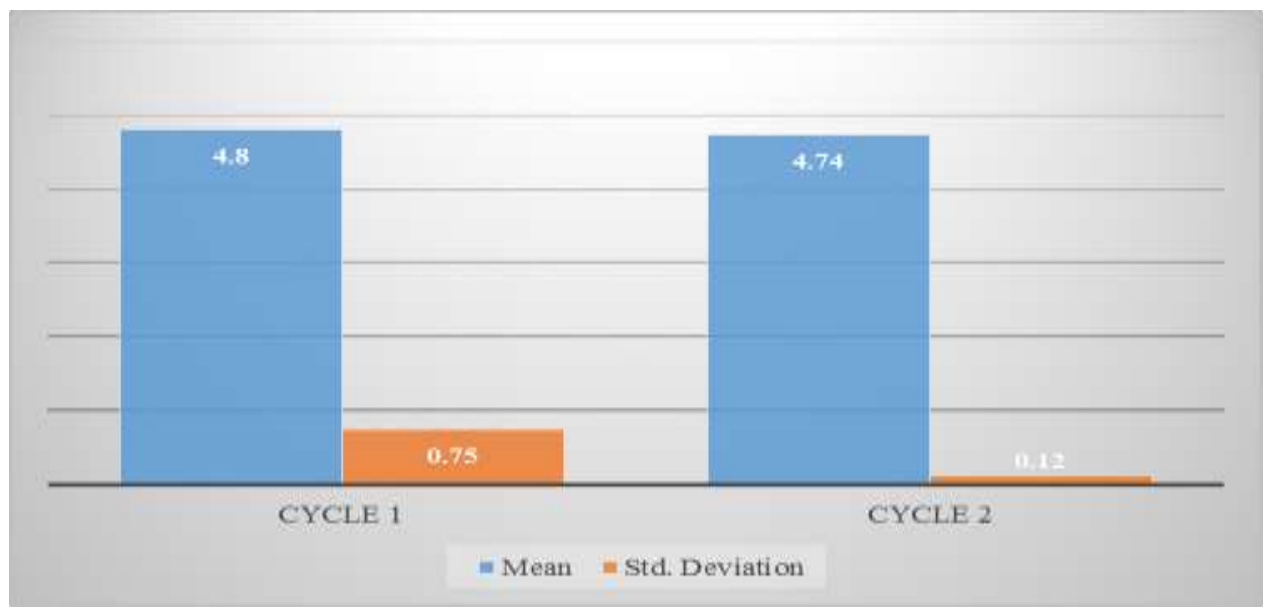

Figure 6. Comparison between both Total Questionnaires Mean in Cycle 1 and Cycle 2

At the end of the cycles, the students have been provided some evaluative feedback through the interview. during this interview, the students explained how their critical thinking skills have been improved by the case study method. The findings revealed students' positive perceptions about the impact of cause study method in enhancing their critical thinking and enhancing their confidence in their abilities.

\section{Discussion and Conclusion}

The purpose of this study was to improve the critical thinking skills of students by case studies method for leadership and group dynamics students in ASU. Based on the research findings, the case study method could enhance students' critical thinking capabilities and enable them to analyze and solve problems during group discussions. The research findings also showed more increase in the number of students critically analyzing and evaluating situations. Moreover, a larger number of students are seen to critically examine, construe, assess, deduce, and do inductive and deductive reasoning as well. The initial study findings stated that the case study encouraged students to reflect, have a discussion with teachers and get involved in group discussions. In addition, the group case study discussion would be more effective than an individual case study for teaching critical thinking and enhancing students' critical thinking abilities.

Group case study promotes the preparation of subject materials to form the critical analysis skills of students. In addition, this group activity supports students' learning and guides them in selecting their perspective field. This is more beneficial for teaching, learning and analyzing the critical thinking process. this research revealed that group 
case study discloses the learning process of students. Case-based teaching is considered a significant approach to developing students' critical thinking skills and decision-making skills. Case studies have significant effects on teaching and learning. Hence, the study findings may identify approaches that could be modified to enhance the quality of higher education institutions. The final conclusion of the research was that it is crucially important to develop the critical thinking abilities of students for better education and enhancement of overall quality in any higher education institution. However, the study limitations include small sample size, as only 40 students participated in the course of leadership and group dynamics. The effectiveness of a lecture is also based on the teacher's performance, which might change in different classes and also get low as the lectures proceed. The test time in class should be according to the course schedule. Although several researches focused on students' critical thinking, the results are insufficient. Therefore, this research came to present a better understanding of the students' critical thinking process and present related theories.

\section{References}

Allen, D. D., \& Toth-Cohen, S. (2019). Use of case studies to promote critical thinking in occupational therapy students. Journal of Occupational Therapy Education, 3(3), 1-18. https://doi.org/10.26681/jote.2019.030309

Bastable, S. B. (2003). Nurse as educator: Principles of teaching and learning for nursing practice. Boston: Jones \& Bartlett Learning.

Behar-Horenstein, L. S., \& Niu, L. (2011). Teaching critical thinking skills in higher education: A review of the literature. Journal of College Teaching and Learning, 8(2), 25-42. https://doi.org/10.19030/tlc.v8i2.3554

Bezanilla, M. J., Fernández-Nogueira, D., Poblete, M., \& Galindo-Domínguez, H. (2019). Methodologies for teaching-learning critical thinking in higher education: The teacher's view. Thinking Skills and Creativity, 33, 100584. https://doi.org/10.1016/j.tsc.2019.100584

Biba, A. (2013). The case study as a type of qualitative research. Journal of Contemporary Educational Studies, l(20), 28-43. https://doi.org/10.1055/s-0029-1217568

Biggs, J., \& Tang, C. (2011). Teaching for quality learning at university (4th ed.). UK: McGraw-Hill Education.

Bonney, K. M. (2013). An Argument and Plan for Promoting the Teaching and Learning of Neglected Tropical Diseases. Journal of Microbiology \& Biology Education, 14(2), 183-188. https://doi.org/10.1128/jmbe.v14i2.631

Bonney, K. M. (2015). Case study teaching method improves student performance and perceptions of learning gains. Journal of Microbiology \& Biology Education, 16(1), 21-28. https://doi.org/10.1128/jmbe.v16i1.846

Bridgman, T., Cummings, S., \& McLaughlin, C. (2016). Restating the case: How revisiting the development of the case method can help us think differently about the future of the business school. Academy of Management Learning and Education, 15(4), 724-741. https://doi.org/10.5465/amle.2015.0291

Carlson, J. A., \& Schodt, D. W. (1995). Beyond the lecture: Case teaching and the learning of economic theory. Journal of Economic Education, 26(1), 17-28. https://doi.org/10.1080/00220485.1995.10844853

Creswell, John W. (2007). Understanding mixed methods research. In J. W. Creswell \& P. V. L.Clark (Eds.), Designing and Conducting Mixed Methods Research, 11, 1-19. Thousand Oaks: California: SAGE.

Devare, S. (2015). Case study: Research method for social sciences. SSRN. Retrieved from ssrn: https://ssrn.com/abstract=2684644

DeYoung, S., \& DeYoung, S. (2003). Teaching strategies for nurse educators. Upper Saddle River, NJ: Prentice Hall Health.

Ebneyamini, S., \& Sadeghi Moghadam, M. R. (2018). Toward developing a framework for conducting case study research. International Journal of Qualitative Methods, 17(1), 1-11. https://doi.org/10.1177/1609406918817954

Facione, P. A. (2006). Critical thinking: What it is and why it counts. Millbrae, CA: California Academic Press.

Fynn, A. E., \& Klein, J. D. (2001). The influence of discussion groups in a case-based learning environment. Educational Technology Research and Development, 49(3), 71-86. https://doi.org/10.1007/BF02504916

Giancarlo, C. A., \& Facione, P. A. (2001). A look across four years at the disposition toward critical thinking among undergraduate students. The Journal of General Education, 50(1), 29-55. https://doi.org/10.1353/jge.2001.0004 
Gibbert, M., Ruigrok, W., \& Wicki, B. (2008). What passes as a rigorous case study? Strategic Management Journal, 29(13), 1465-1474. https://doi.org/10.1002/smj.722

Grupe, F. H., \& Jay, J. K. (2000). Incremental cases: Real-life, real-time problem solving. College Teaching, 48(4), 123-128. https://doi.org/10.1080/87567550009595828

Hammond, J. S. (2002). Learning by the case method. Harvard Business School, (October), 1-4.

Herreid, C. F., Schiller, N. A., Herreid, K. F., \& Wright, C. (2011). In case you are interested: Results of a survey of case study teachers. Journal of College Science Teaching, 40(4), 76-80.

Ignatavicius, D. D. (2001). Six critical thinking skills for at-the-bedside success. Dimensions of Critical Care Nursing, 20(2), 30-33. https://doi.org/10.1097/00003465-200103000-00008

Kaddouro, M. A. (2011). Critical thinking skills of nursing students in lecture-based teaching and case-based learning. International Journal for the Scholarship of Teaching and Learning, 5(2), 1-18. https://doi.org/10.20429/ijsotl.2011.050220

Knechel, W. R. (1992). Using the case method in accounting instruction. Issues in Accounting Education, 7(2), $205-217$.

Leenders, M. R., Mauffette-Leenders, L. A., \& Erskine, J. A. (2001). Writing cases (4th ed.). Ivey Publishing, Richard Ivey School of Business.

Meyer, P. (2002). Precision journalism: A reporter's introduction to social science methods (4th ed.). Boston: Rowman \& Littlefied Publishers, Inc.

Murray-Nseula, M. (2011). Incorporating case studies into an undergraduate genetics course. Journal of the Scholarship of Teaching and Learning, 11(3), 75-85.

Myrick, F. (2002). Preceptorship and critical thinking in nursing education. Journal of Nursing Education, 41(4), 154-164. https://doi.org/10.3928/0148-4834-20020401-05

Nieto, A. M., \& Saiz, C. (2011). Skills and dispositions of critical thinking: Are they sufficient? Anales de Psicologia, 27(1), 202-209. https://doi.org/10.5840/inquiryct20122713

Paul, R. (1993). Critical Thinking: How to Prepare Students for a Rapidly Changing World (1st ed.). California: Foundation for Critical Thinking, Santa Rosa.

Paul, Richard, \& Elder, L. (2013). Critical thinking: Tools for taking charge of your professional and personal life. London, England: FT Press.

Petress, K. (2004). Critical thinking: An extended definition. Education, 124(3), $461-467$. https://doi.org/10.1007/BF00128143

Pilz, M., \& Zenner, L. (2018). Using case studies in business education to promote networked thinking: findings of an intervention study. Teaching in Higher Education, 23(3), 325-342. https://doi.org/10.1080/13562517.2017.1382467

Popil, I. (2011). Promotion of critical thinking by using case studies as teaching method. Nurse Education Today, 31(2), 204-207. https://doi.org/10.1016/j.nedt.2010.06.002

Profetto-McGrath, J. (2003). The relationship of critical thinking skills and critical thinking dispositions of baccalaureate nursing students. Journal of Advanced Nursing, 43(6), 569-577. https://doi.org/10.1046/j.1365-2648.2003.02755.X

Schmaltz, R. M., Jansen, E., \& Wenckowski, N. (2017). Redefining Critical Thinking: Teaching Students to Think like Scientists. Frontiers in Psychology, 8, 459. https://doi.org/10.3389/fpsyg.2017.00459

Scoles, J., Huxham, M., \& McArthur, J. Mixed-Methods Research in Education: Exploring Students' Response to a Focused Feedback Initiative (2014). SAGE Research Methods Cases. https://doi.org/10.4135/978144627305013514690

Shareia, B. F. (2015). Qualitative and quantitative case study Research Method on social science: Accounting Perspective. International Journal of Social, Management, Economics, and Business Engineering, 9(12), 3873-3877.

Soukup, F. (1999). Assessment of Critica thinking Skills in associate degree nursing students. University of Wisconsin - Stout, US. 
Taleb, H. M., \& Chadwick, C. (2016). Enhancing student critical and analytical thinking skills at a higher education level in developing countries: Case study of the British university in Dubai. Journal of Educational and Instructional Studies in the World, 6(1), 67-77.

Tight, M. (2010). The curious case of case study: a viewpoint. International Journal of Social Research Methodology, 13(4), 329-339. https://doi.org/10.1080/13645570903187181

Tilus, G. (2012). 6 Critical Thinking Skills You Need to Master Now.

Vora, M. B., \& Shah, C. J. (2015). Case-based learning in pharmacology: Moving from teaching to learning. International Journal of Applied \& Basic Medical Research, 5(Suppl 1), S21-S23. https://doi.org/10.4103/2229-516X.162259

Walker, S. E. (2003). Active learning strategies to promote critical thinking. Journal of Athletic Training, 38(3), 263-267.

White, T. K., Whitaker, P., Gonya, T., Hein, R., Kroening, D., Lee, K., \& Hayes, E. (2009). The use of interrupted case studies to enhance critical thinking skills in biology. Ournal of Microbiology \& Biology Education: JMBE, 10(1), 25-31. https://doi.org/10.1128/jmbe.v10.96

Yadav, A., Deschryver, M., Dirkin, K., Schiller, N. A., Maier, K., \& Herreid, C. F. (2007). Teaching science with case studies: A national survey of faculty perceptions of the benefits and challenges of using cases. Journal of College Science Teaching, 37(1), 34-38.

Yin, R. K. (2003). Case Study Research (3rd ed.). London: SAGE Publications.

Youngblood, N., \& Beitz, J. M. (2001). Developing critical thinking with active learning strategies. Nurse Educator, 26(1), 39-42. https://doi.org/10.1097/00006223-200101000-00016

Zelaieta Anta, E., \& Camino Ortiz de Barrón, I. (2018). The development of critical thinking in the initial teacher training Analysis of a pedagogical strategy from the students' vision. Journal of Curriculum and Teacher Training, 22(1), 197-214. https://doi.org/10.30827/profesorado.v22i1.9925

Zhang, D., Wang, L., Lv, F., Su, W., Liu, Y., Shen, R., \& Bi, P. (2007). Advantages and challenges of using census and multiplier methods to estimate the number of female sex workers in a Chinese city. AIDS Care, 19(1), 17-19. https://doi.org/10.1080/09540120600966158 